\title{
Joint estimation of genetic parameters for test-day somatic cell count and mastitis in the United Kingdom
}

\author{
R. Mrode, ${ }^{1}$ T. Pritchard, ${ }^{1,2}$ M. Coffey, and E. Wall \\ Animal \& Veterinary Sciences, Scottish Agricultural College (SAC), Easter Bush, Midlothian, EH25 9RG, United Kingdom
}

\begin{abstract}
Genetic parameters were estimated in a joint analysis of $\log _{\mathrm{e}}$-transformed somatic cell count (TSCC) with either mastitis as a binary trait (MAS) or the number of mastitis cases (NMAS) in Holstein-Friesian cows for the first 3 lactations using a random regression model. In addition, a multi-trait analysis of MAS and NMAS was also implemented. There were $67,175,30,617$, and 16,366 cows with records for TSCC, MAS, and NMAS in lactations 1,2 , and 3, respectively. The frequency of MAS was 14, 20, and $25 \%$ in lactations 1, 2, and 3 respectively. The model for TSCC included herdtest-day, age at calving and month of calving, fixed lactation curves nested with calving year groups, and random regressions with Legendre polynomials of order 2 for animal and permanent environmental effects. The model for MAS and NMAS included fixed herdyear-season, age at calving and month of calving, and random animal and permanent environmental effects. All analyses were carried out using Gibbs sampling. Estimates of mean daily heritability averaged over a 305-d lactation were $0.11,0.14$, and 0.15 for TSCC for lactations 1, 2, and 3, respectively. Corresponding heritability estimates for MAS were 0.05, 0.07, and 0.09. The heritabilities for NMAS were similar at 0.06, 0.07, and 0.12 , respectively, for lactations 1,2 , and 3 . The genetic correlations between lactations 1 and 2, 1 and 3 , and 2 and 3 were $0.75,0.64$, and 0.92 for computed 305-d lactation TSCC; 0.55, 0.48, and 0.89 for MAS; and $0.62,0.42$, and 0.85 for NMAS, respectively. The genetic correlations between MAS and TSCC were positive and generally moderate to high. The genetic correlations between computed 305-d lactation TSCC and MAS were $0.53,0.61$, and 0.68 in lactations 1,2 , and 3 , respectively. Similar corresponding genetic correlations were obtained between computed 305-d lactation TSCC and NMAS in the respective parities. Mastitis
\end{abstract}

\footnotetext{
Received September 23, 2011.

Accepted March 19, 2012.

${ }^{1}$ These authors made equal contributions to this work.

${ }^{2}$ Corresponding author: Tracey.Pritchard@sac.ac.uk
}

as a binary trait and NMAS in the same lactation were very highly correlated and were genetically the same trait. It is intended that the new parameters will be used in setting up a national evaluation system for the joint analysis of TSCC and MAS.

Key words: somatic cell count, mastitis, genetic parameter

\section{INTRODUCTION}

Mastitis is a recurrent and costly disease for dairy farms worldwide, affecting production, welfare, and the quality of milk produced. For many years, selection indices worldwide have focused mainly on increasing milk production, to satisfy consumer demand for an abundance of animal products at low cost. This has been extremely successful through a combination of genetic selection and improved management, but has simultaneously led to negative effects on health, reproduction, and longevity (Oltenacu and Broom, 2010), which directly influence the costs of production. In addition, public perception of milk production is becoming increasingly important due to concerns about the welfare of milking cows. Hence, cows with a higher incidence of mastitis, shorter milking lives due to involuntary culling, and higher antibiotic usage do not present a good image of the dairy industry.

Thus, selection indices have evolved recently by focusing on a broader and balanced breeding goal to include more functional traits (Miglior et al., 2005). Breeding for reduced incidence of mastitis can be achieved by direct selection based on clinical mastitis records, by indirect selection using genetically correlated traits, or a combination of both. The udder health subindex in the UK national Profitable Lifetime Index (£PLI) includes lactation average SCC and the mammary composite trait. Due to a deficiency of mastitis recording in many countries, SCC has been used widely as an indicator trait for both clinical and subclinical mastitis. Somatic cell count is considered a suitable indirect trait as it is routinely measured objectively by automated devices, has higher heritability than mastitis, and is positively genetically correlated with mastitis (Detilleux, 2009). From a range of studies on Nordic field data, genetic 
correlations between mastitis and SCC ranged from 0.3 to 0.8 , with an average genetic correlation of 0.6 (Heringstad et al., 2000). The less than unity genetic correlation implies that additional genetic gain could be achieved by the use of mastitis records. Therefore, efforts to reduce mastitis incidence by genetic improvement are expected to be more effective if mastitis were routinely recorded, evaluated, and selected for directly (Banos et al., 2006), together with indirect selection (e.g., SCC and udder conformation traits; Lund et al., 1994; Kadarmideen and Pryce, 2001; Bloemhof et al., 2009). Selection based on combined mastitis and SCC records was found to be $20 \%$ more efficient than on SCC alone in a Swedish study (Philipsson et al., 1995).

There has been a lack of recorded data for clinical mastitis in the United Kingdom (Mrode and Swanson, 2003). With the exception of Nordic countries, which have national health-recording systems, the use of clinical mastitis as a breeding goal trait is limited worldwide (Heringstad et al., 2000; Interbull, 2009). However, some UK herds have been voluntarily recording clinical mastitis through milk recording organizations (Kadarmideen et al., 2001) and levels of recording in more recent years have increased due to a combination of the uptake of on-farm software for herd management, increases in farm assurance schemes (in the United Kingdom), and the requirement to record veterinary treatments on food-producing animals.

The definition of mastitis used to estimate genetic parameters differ greatly among studies. Generally, mastitis is classified as a binary trait, with 1 and 0 indicating presence or absence of the disease, respectively. Some analyses have included the number of clinical cases per lactation (Sørensen et al., 2000; Vazquez et al., 2009), or the number of days from calving to the first mastitis incidence (Carlén et al., 2005). In addition, the period used for measuring mastitis incidence varies greatly, commencing from a period before calving to the end of lactation, or at different points up to the end of lactation (Gasqui and Barnouin, 2003). Also, lactation length is sometimes split into successive periods so that multiple cases of mastitis and the timing of the event are taken into account, and results from such studies have concluded that mastitis is not the same trait genetically throughout the lactation (Chang et al., 2004; Carlén et al., 2009). Moreover, an analysis incorporating information from later parities is regarded as important, as mastitis incidence increases with parity and analyses have indicated that mastitis in different parities are different traits (Carlén et al., 2004; Heringstad et al., 2004).

Previous work using farmer-recorded mastitis events include studies on UK data (Kadarmideen et al.,
2000), US data (Zwald et al., 2004), Australian data (Haile-Mariam and Goddard, 2010), and Canadian data (Neuenschwander, 2010) and they demonstrate their possible use in future national genetic evaluations. Kadarmideen et al. (2001) estimated genetic parameters for mastitis in Holstein-Friesians in the United Kingdom; however, until recent years, sufficient data on mastitis was lacking for national evaluations. Although the number of mastitis records are increasing, they are as yet inadequate to justify ignoring the volume of data on SCC; therefore, a joint analysis of both traits seems the optimum approach. Although Mrode and Swanson (2003) estimated genetic parameters for $\log _{\mathrm{e}}$-transformed SCC (TSCC) in the United Kingdom, using a random regression model, data was limited and the genetic relationship between TSCC and mastitis was not examined. Therefore, this paper estimates genetic parameters in the first 3 lactations for TSCC and mastitis using a random regression model. Mastitis was included in the analysis either as a binary trait (MAS) or as the total number of mastitis cases (NMAS) within a lactation.

\section{MATERIALS AND METHODS}

\section{Data}

The recording of mastitis events used in this study was performed by farmers on a voluntary basis as part of routine milk recording and the data was made available by milk-recording organizations. The data set for mastitis and test-day SCC consisted of the first 3 lactations of Holstein-Friesian cows, calving from 1996 to 2009. All herds with any mastitis records were selected and herd-year-season subclasses were formed. Corresponding records for test-day SCC for the herds were included in the data set. The calving year was defined from April to March and 2 season groups (April to September and October to March) were formed. The following general edits were implemented in creating the data set used for the final analysis: 1) calving ages for first, second, and third parity were within the ranges of 18 to $42 \mathrm{mo}$, 30 to $62 \mathrm{mo}$, and 42 to $70 \mathrm{mo}$, respectively; 2) sires were born from 1992 onwards; 3) sires had at least 20 eligible daughters and of these, up to the first 250 daughters born were selected; 4) test-day records were taken from 4 to $305 \mathrm{~d}$ of calving, each animal required at least 6 test-day records per lactation, and the first 12 test-day records were included for SCC; 5) there were at least 5 animals per herd-year-season; 6 ) at least 1 animal was affected by mastitis per herd-year-season; 7) at least $1 \%$ of animals were affected by mastitis per herd-yearseason; and 8) every animal required data in lactation 
Table 1. Summary statistics of analyzed data

\begin{tabular}{lccccc}
\hline Lactation & $\begin{array}{c}\text { No. of } \\
\text { cows }\end{array}$ & $\begin{array}{c}\text { No. of test- } \\
\text { day records }\end{array}$ & $\begin{array}{c}\text { Mean SCC } \\
(1,000 \text { cells } / \mathrm{mL})\end{array}$ & $\begin{array}{c}\text { Mean } \log _{\mathrm{e}^{-}} \\
\text {transformed SCC }\end{array}$ & $\begin{array}{c}\text { Mastitis } \\
\text { frequency }^{1}\end{array}$ \\
\hline 1 & 67,175 & 615,844 & 136.24 & 11.82 & 13.5 \\
2 & 30,617 & 279,971 & 165.25 & 12.02 & 20.0 \\
3 & 16,366 & 149,468 & 210.41 & 12.26 & 24.5 \\
\hline
\end{tabular}

${ }^{1}$ Percentage of cows with at least 1 mastitis case during lactation.

1. After editing, the data set consisted of records from 67,175 cows sired by 4,785 bulls. The animal pedigree file was generated by tracing the pedigrees of cows 3 generations back. The resulting pedigree file contained the relationship of 165,142 animals.

\section{Trait Definition}

In the present study, mastitis events recorded from 0 to $305 \mathrm{~d}$ after calving were considered. Mastitis was coded in 2 different ways to create 2 traits. For the first trait, mastitis (MAS) was coded as a binary trait; with affected animals classed as 1, irrespective of the number of mastitis episodes recorded within that lactation and nonaffected animals were classed as 0 . The second trait examined the number mastitis cases during each lactation (NMAS). A mastitis case was considered to be a new case when no other mastitis events had been recorded during the preceding $8 \mathrm{~d}$, based upon recommendations of Kelton et al. (1998). The categories for NMAS were 0 (no cases), $1,2,3,4$, and 5 ( 5 or more cases). The test-day SCC used in the analysis was $\log _{\mathrm{e}}$ transformed (TSCC). Summary statistics of the analyzed data are given in Tables 1 and 2 .

\section{Model}

A multi-trait multiple lactation random regression animal model was applied for the joint analysis of data for TSCC and MAS or NMAS records in the first 3 lactations. The observations from each lactation for each of the traits were treated as separate traits. The model

Table 2. Proportion of cows with $0,1,2,3,4$, and $5+$ mastitis cases during lactation

\begin{tabular}{lccc}
\hline $\begin{array}{l}\text { Number } \\
\text { of mastitis } \\
\text { cases }\end{array}$ & Lactation 1 & Lactation 2 & Lactation 3 \\
\hline 0 & 86.4 & 80.4 & 75.5 \\
1 & 10.6 & 13.4 & 16.4 \\
2 & 2.1 & 4.0 & 5.0 \\
3 & 0.6 & 1.3 & 1.8 \\
4 & 0.2 & 0.5 & 0.7 \\
$5+$ & 0.1 & 0.4 & 0.6 \\
\hline
\end{tabular}

for TSCC and MAS or NMAS in the lth lactation in matrix notation was:

$$
\left[\begin{array}{l}
\mathbf{y}_{1} \\
\mathbf{y}_{2}
\end{array}\right]=\left[\begin{array}{ll}
\mathbf{X}_{1} & 0 \\
0 & \mathbf{X}_{2}
\end{array}\right]\left(\begin{array}{l}
\mathbf{b}_{1} \\
\mathbf{b}_{2}
\end{array}\right)+\left[\begin{array}{ll}
\mathbf{Z}_{1} & 0 \\
0 & \mathbf{Z}_{2}
\end{array}\right]\left(\begin{array}{l}
\mathbf{a}_{1} \\
\mathbf{a}_{2}
\end{array}\right)+\left[\begin{array}{ll}
\mathbf{W}_{1} & 0 \\
0 & \mathbf{W}_{2}
\end{array}\right]\left(\begin{array}{l}
\mathbf{p}_{1} \\
\mathbf{p}_{2}
\end{array}\right)+\left[\begin{array}{l}
\mathbf{e}_{1} \\
\mathbf{e}_{2}
\end{array}\right]
$$

where $\mathbf{y}_{1}$ and $\mathbf{y}_{2}$ are vectors of TSCC test-day records and MAS or NMAS for the cow; $\mathbf{b}_{1}$ and $\mathbf{b}_{2}$ are vectors of fixed effects of age at calving and month at calving common to both traits $\left(\mathbf{b}_{1}\right.$ has additional fixed effect for herd-test-day and fixed regression coefficients nested within calving year groupings for TSCC and $\mathbf{b}_{2}$ additional fixed effect for herd-year-season of calving for MAS or NMAS); $\mathbf{Z}_{1}\left(\mathbf{W}_{1}\right)$ and $\mathbf{Z}_{2}\left(\mathbf{W}_{2}\right)$ are matrices of orthogonal polynomials of order 2 and 0 , respectively for TSCC and MAS or NMAS; $\mathbf{a}$ and $\mathbf{p}$ are vectors of animal and permanent environmental (pe) random regression effects, respectively; and $\mathbf{e}$ is the vector residual errors. The fixed curves were nested within 4 calving year groupings (1996-1999, 2000-2003, 2004-2006, and 2007-2009) within lactation and residual variances were estimated for 4 different classes within lactation: 4 to 24,25 to 49,50 to 249 , and 250 to 305 DIM. Using Equation 1 for the joint analysis of TSCC and MAS or NMAS in the first 3 lactations as different traits, it was assumed that the variance of $\mathbf{a}$ was $\mathbf{A} \otimes \mathbf{G}$, the variance of $\mathbf{p}$ was $\mathbf{I} \otimes \mathbf{P}$ and variance of $\mathbf{e}$ was $\mathbf{I} \sigma^{2}$ e, where $\mathbf{A}$ is the numerator relationship matrix; $\mathbf{G}$ and $\mathbf{P}$ are the covariance matrices of order 12 for additive genetic animal effects and pe effects, respectively; and $\otimes$ is the Kronecker product. The use of a polynomial of order 2 to model additive animal genetic and pe effects was based on a previous study by Mrode and Swanson (2003), who examined the fitting of different orders of orthogonal polynomials. In addition, it is computationally feasible and generally in line with what is implemented in test-day models for national evaluation in many countries (Interbull, 2009).

A joint analysis of MAS and NMAS in the first 3 lactations was carried out, treating observations in each of the 3 lactations as separate traits, fitting the model for $\mathbf{y}_{2}$ in Equation 1 for each trait. Thus, the variance of $\mathbf{a}$ and $\mathbf{p}$ were $\mathbf{A} \otimes \mathbf{G}$ and $\mathbf{I} \otimes \mathbf{P}$, respectively, where $\mathbf{G}$ 
and $\mathbf{P}$ covariance matrix additive genetic animal effects and pe effects were of order 6 .

All analyses were implemented using the Gibbs sampling algorithm based on Gauss-Seidel iterative best linear unbiased prediction scheme for solving the mixed model equations. A flat prior was assumed for the fixed effects and sampling was blockwise. A uniform prior distribution was assumed for $\mathbf{a}$ and $\mathbf{p}$, and sampling was blockwise per animal from the full conditional distribution, which is proportional to a scaled inverted chi-squared distribution. The chain length of 120,000 was generated, of which the first 40,000 were discarded as burn-in period. Convergence was monitored by plots of the marginal posterior means of some of the parameters during the iterative process. The choice of the chain length and burn-in period was based on the plots and results from a previous analysis (Mrode and Swanson, 2003). One out of the 5 iterations was then saved and the marginal posterior means obtained were regarded as estimates of variance and covariance components. Genetic variances and heritabilities for TSCC and covariances between TSCC and MAS or NMAS at different DIM were calculated from the covariance matrices generated from the random regression solutions for animal, pe, and residual effects. The heritability for TSCC in lactation $i$ for the $j$ th DIM was computed as $\left(\mathbf{z}^{\prime}{ }_{1 j} \mathbf{G}_{i i} \mathbf{z}_{1 j}+\mathbf{w}^{\prime}{ }_{1 j} \mathbf{P}_{i i} \mathbf{w}_{1 j}+\sigma^{2} \mathrm{e}_{i}\right)^{-1}\left(\mathbf{z}^{\prime}{ }_{1 j} \mathbf{G}_{i i} \mathbf{z}_{1 j}\right)$, where $\mathbf{z}_{1 j}$ $\left(\mathbf{w}_{1 j}\right)$ is the vector of orthogonal polynomials of day $j$ in milk or is the sum of vector of orthogonal polynomials for $\mathrm{d} 4$ to 305 when heritability is on a 305-d basis and $\mathbf{G}_{i i}\left(\mathbf{P}_{i i}\right)$ is the $3 \times 3$ submatrix of $\mathbf{G}(\mathbf{P})$ for the $i$ th lactation. The same formula is used to compute heritabilities for MAS or NMAS but $\mathbf{G}_{i i}\left(\mathbf{P}_{i i}\right)$ is of order 1 and $\mathbf{z}_{1 j}\left(\mathbf{w}_{1 j}\right)$ is replaced with the scalar $\mathbf{z}_{2}\left(\mathbf{w}_{2}\right)$. The genetic correlation between TSCC in lactations $i$ and $k$ on the $j$ th DIM was computed as

$$
\mathbf{z}_{1 j}^{\prime} \mathbf{G}_{i k} \mathbf{z}_{1 j} / \sqrt{\left[\left(\mathbf{z}^{\prime}{ }_{1 j} \mathbf{G}_{i i} \mathbf{z}_{1 j}\right)\left(\mathbf{z}^{\prime}{ }_{1 j} \mathbf{G}_{k k} \mathbf{z}_{1 j}\right)\right]}
$$

where $\mathbf{G}_{i k}$ is the $3 \times 3$ submatrix of $\mathbf{G}$ between $i$ th and $k$ th lactation. In the case of the genetic correlation between MAS or NMAS in lactation $i$ and $k, \mathbf{z}_{1 j}$ in the above formula is replaced by the scalar $\mathbf{z}_{2}$. Genetic correlations between TSCC at jth DIM in parity $i$ and MAS or NMAS in lactation $k$ were computed as

$$
\mathbf{z}_{1 j}^{\prime} \mathbf{G}_{i k} \mathbf{z}_{2} / \sqrt{\left[\left(\mathbf{z}^{\prime}{ }_{1 j} \mathbf{G}_{i i} \mathbf{z}_{1 j}\right)\left(\mathbf{z}_{2}^{\prime} \mathbf{G}_{k k} \mathbf{z}_{2}\right)\right]},
$$

where $\mathbf{G}_{i k}$ is the $3 \times 1$ submatrix of $\mathbf{G}$ between TSCC $i$ th and MAS or NMAS in the $k$ th lactation.

\section{RESULTS}

\section{Frequency of Mastitis and the Number of Mastitis Cases}

The overall frequency of MAS across the first 3 lactations was $16.7 \%$ and the frequency increased with lactation number with estimates of 13.5, 20.0, and $24.5 \%$ for lactations 1, 2, and 3, respectively (Table 1). Also, the number of mastitis cases increased with parity (Table 2).

\section{Heritabilities}

The estimates of daily heritability for TSCC in all 3 lactations at different DIM are illustrated in Figure 1. Generally, daily heritabilities increased with DIM in all parities but were highest in lactation 2 at the end of the lactation. The mean daily heritabilities averaged over 305-d lactation period, were $0.11,0.14$, and 0.15 , respectively, for lactations 1,2 , and 3 . The heritability of MAS increased with lactation number and estimates were $0.05,0.07$, and 0.09 in lactations 1,2 , and 3 , respectively (Table 3 ). Corresponding estimates for NMAS were $0.06,0.07$, and 0.12 (Table 4 ). These heritability estimates for MAS and NMAS were obtained from the joint analysis of either trait with TSCC and are slightly higher than corresponding estimates for MAS (0.04, 0.06, and 0.08) and NMAS (0.05, 0.07, and $0.10)$ from analysis of both MAS and NMAS together (Table 5).

\section{Genetic Correlations}

The estimates of genetic correlations within lactations for some selected DIM for TSCC are given in Tables 3 and 4. As expected, the genetic correlations within lactations were highest between adjacent DIM, usually about 0.97 to 0.98 and decreased as DIM got further apart. In general, the within-lactation genetic correlations were higher within the first lactation relative to the other lactations, even when DIM were farther apart. For instance, the genetic correlations between d 60 and 300 was 0.55 in the first lactation compared with corresponding values of 0.27 and 0.11 in second and third lactations, respectively. The decrease in genetic correlations as DIM got further apart was greatest within the third lactation.

The genetic correlations for TSCC between lactations 2 and 3 at the same DIM were highest, ranging from 0.88 to 0.94 , and showed little variation at different stages of lactation; however, different patterns were observed between lactations 1 and 2, and 1 and 3 (Figure 2). The 
Table 3. Heritabilities (on diagonal), genetic correlations (below diagonal), and phenotypic correlations (above diagonal) on selected DIM for analysis between $\log _{\mathrm{e}}$-transformed SCC (TSCC1, TSCC2, and TSCC3) and mastitis (MAS1, MAS2, and MAS3) in lactations 1, 2, and $3^{1}$

\begin{tabular}{|c|c|c|c|c|c|c|c|c|c|c|c|c|c|}
\hline \multirow[b]{2}{*}{ Item } & \multirow[b]{2}{*}{ DIM } & \multicolumn{3}{|c|}{ TSCC1 } & \multicolumn{3}{|c|}{ TSCC2 } & \multicolumn{3}{|c|}{ TSCC3 } & \multirow[b]{2}{*}{ MAS1 } & \multirow[b]{2}{*}{ MAS2 } & \multirow[b]{2}{*}{ MAS3 } \\
\hline & & 30 & 150 & 300 & 30 & 150 & 300 & 30 & 150 & 300 & & & \\
\hline TSCC1 & 300 & 0.45 & 0.80 & 0.15 & 0.15 & 0.19 & 0.19 & 0.15 & 0.17 & 0.12 & 0.11 & 0.07 & 0.08 \\
\hline \multirow[t]{2}{*}{ TSCC2 } & 30 & 0.48 & 0.58 & 0.57 & 0.11 & 0.38 & 0.14 & 0.23 & 0.16 & 0.01 & 0.08 & 0.20 & 0.08 \\
\hline & 150 & 0.58 & 0.72 & 0.69 & 0.67 & 0.13 & 0.34 & 0.16 & 0.25 & 0.20 & 0.09 & 0.20 & 0.10 \\
\hline \multirow{2}{*}{ TSCC3 } & 150 & 0.47 & 0.62 & 0.59 & 0.61 & 0.93 & 0.61 & 0.64 & 0.13 & 0.31 & 0.08 & 0.11 & 0.18 \\
\hline & 300 & 0.52 & 0.59 & 0.36 & 0.01 & 0.61 & 0.88 & -0.06 & 0.57 & 0.20 & 0.05 & 0.06 & 0.08 \\
\hline MAS1 & & 0.47 & 0.54 & 0.37 & 0.52 & 0.59 & 0.30 & 0.52 & 0.56 & 0.29 & 0.05 & 0.10 & 0.07 \\
\hline MAS2 & & 0.66 & 0.61 & 0.48 & 0.67 & 0.56 & 0.30 & 0.66 & 0.70 & 0.39 & 0.55 & 0.07 & 0.12 \\
\hline MAS3 & & 0.46 & 0.41 & 0.29 & 0.60 & 0.47 & 0.11 & 0.69 & 0.67 & 0.15 & 0.48 & 0.89 & 0.09 \\
\hline
\end{tabular}

${ }^{1}$ Standard deviations for heritabilities were 0.01 for TSCC and $<0.02$ for MAS in all lactations. Standard deviations for genetic correlations were 0.03 to 0.04 for most estimates, with the highest value of 0.07 between 30 and 300 DIM in the third lactation. Standard deviations for phenotypic correlations were $<0.03$.

genetic correlations for TSCC for the same DIM in first and second lactations were of medium value, ranging from 0.48 to 0.72 , peaking at about 150 to 180 , with values being lower for DIM at the beginning and end of the lactation. Although corresponding genetic correlations between first and third lactations followed the same pattern as above, values were much lower (e.g., 0.35 at the beginning and end of the lactation). The genetic correlations between lactations 1 and 2, 1 and 3 , and 2 and 3 computed for 305-d lactation TSCC were $0.75,0.64$, and 0.92 , respectively, further confirming the higher genetic correlation between second and third lactation. The genetic correlations among MAS or NMAS across the 3 lactations followed a similar pattern but were slightly lower in value than TSCC. The genetic correlations between lactations 1 and 2, 1 and 3 , and 2 and 3 were $0.55,0.48$, and 0.89 for MAS (Table 3 ), and were $0.62,0.42$, and 0.85 for NMAS, respectively (Table 4 ).

The genetic correlations between TSCC at DIM and MAS within lactations were, in general, of medium values and ranged from 0.37 to $0.55,0.30$ to 0.68 , and 0.15 to 0.75 for first, second, and third lactation, respectively (Table 3 and Figures 3, 4, and 5). Genetic correlations were lowest between TSCC and MAS at 300 DIM. The trend of genetic correlations between TSCC and MAS with DIM observed in the first and third lactations was similar; genetic correlations increased with DIM,

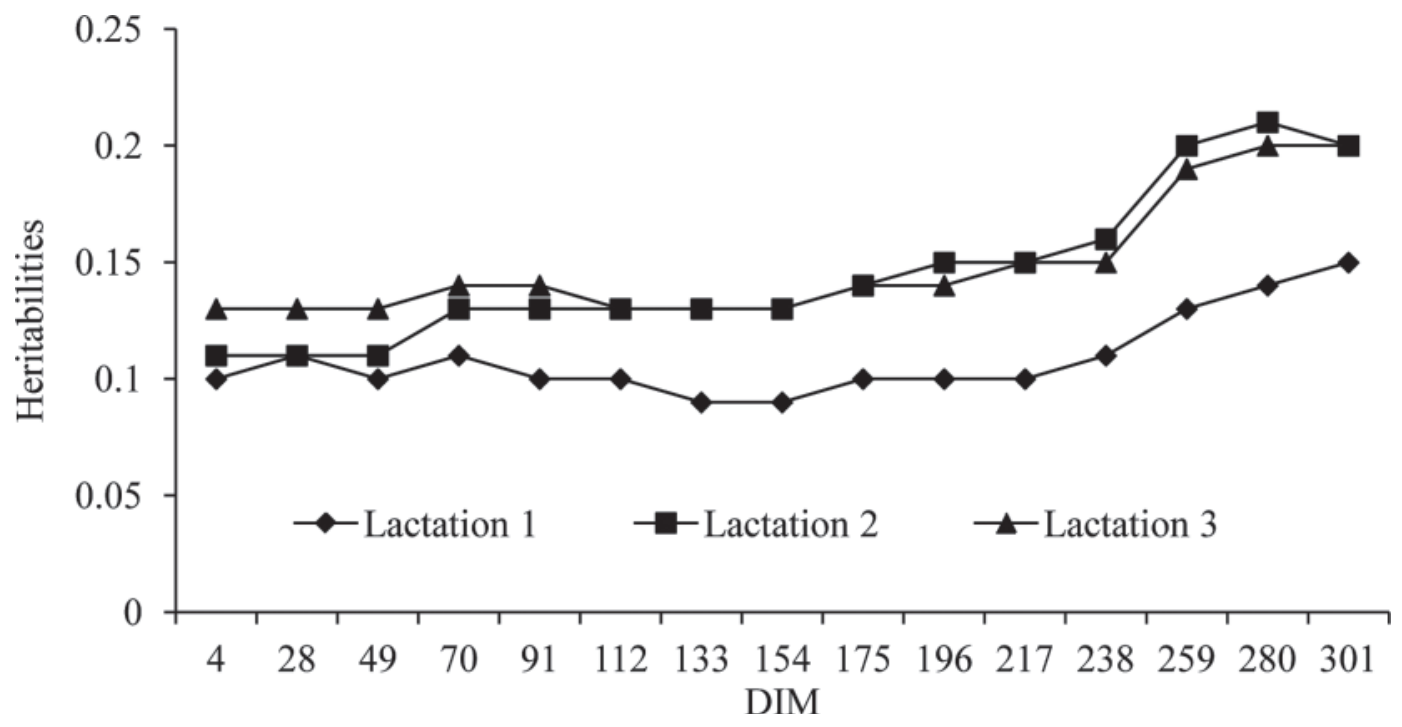

Figure 1. Daily heritabilities for $\log _{\mathrm{e}}$-transformed SCC in the first 3 lactations. 


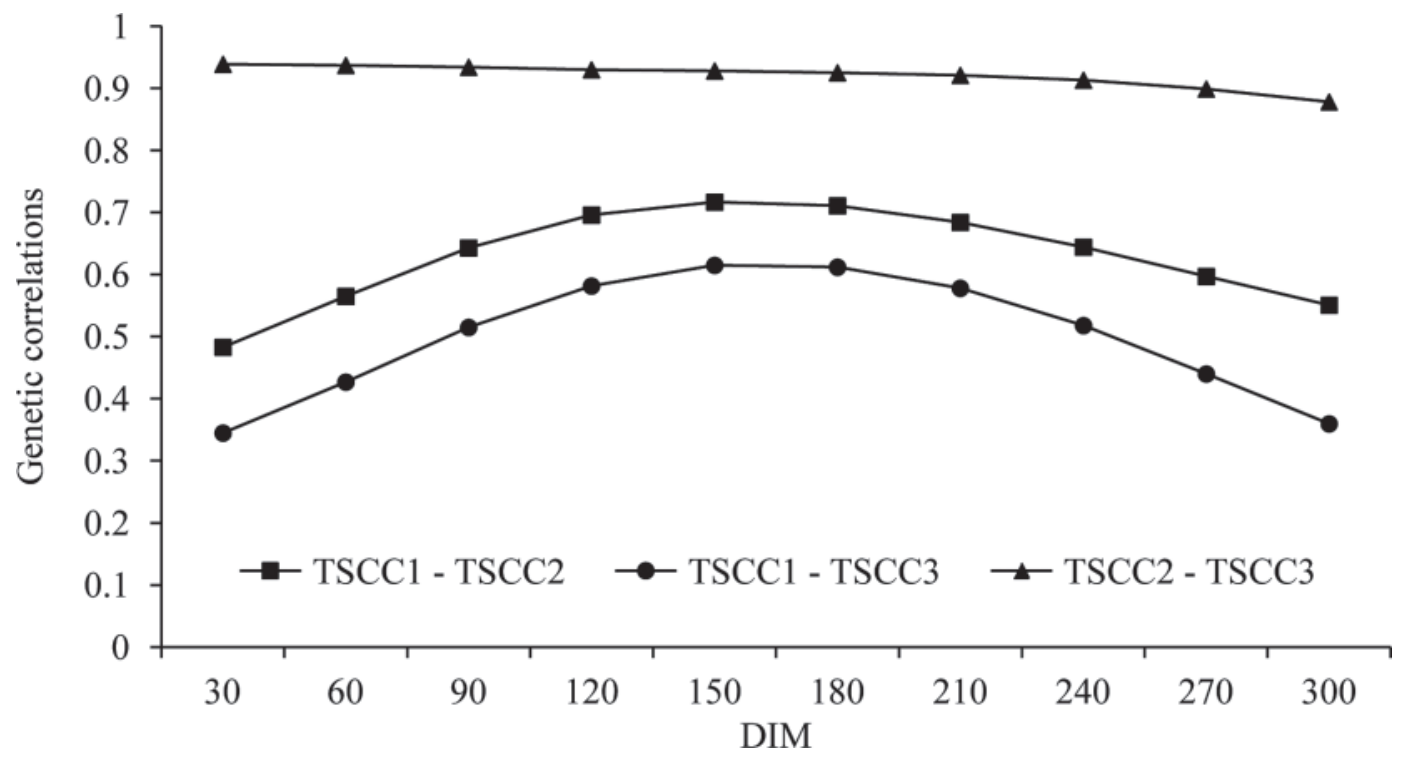

Figure 2. Genetic correlations for $\log _{\mathrm{e}}$-transformed SCC (TSCC1, TSCC2, and TSCC3) for the same DIM across lactations 1,2 , and 3.

Table 4. Heritabilities (on diagonal), genetic correlations (below diagonal), and phenotypic correlations (above diagonal) on selected DIM for analysis between $\log _{\mathrm{e}}$-transformed SCC (TSCC1, TSCC2, and TSCC3) and number of mastitis cases (NMAS1, NMAS2, and NMAS3) in lactations 1,2 , and 3

\begin{tabular}{|c|c|c|c|c|c|c|c|c|c|c|c|c|c|}
\hline \multirow[b]{2}{*}{ Item } & \multirow[b]{2}{*}{ DIM } & \multicolumn{3}{|c|}{ TSCC1 } & \multicolumn{3}{|c|}{ TSCC2 } & \multicolumn{3}{|c|}{ TSCC3 } & \multirow[b]{2}{*}{ NMAS1 } & \multirow[b]{2}{*}{ NMAS2 } & \multirow[b]{2}{*}{ NMAS3 } \\
\hline & & 30 & 150 & 300 & 30 & 150 & 300 & 30 & 150 & 300 & & & \\
\hline \multirow{2}{*}{ TSCC1 } & 150 & 0.76 & 0.09 & 0.40 & 0.12 & 0.15 & 0.19 & 0.10 & 0.14 & 0.17 & 0.16 & 0.09 & 0.06 \\
\hline & 300 & 0.45 & 0.80 & 0.15 & 0.15 & 0.19 & 0.19 & 0.14 & 0.17 & 0.12 & 0.12 & 0.09 & 0.07 \\
\hline \multirow[t]{2}{*}{ TSCC2 } & 30 & 0.47 & 0.57 & 0.57 & 0.11 & 0.38 & 0.14 & 0.23 & 0.17 & 0.02 & 0.09 & 0.21 & 0.09 \\
\hline & 150 & 0.57 & 0.70 & 0.69 & 0.66 & 0.13 & 0.34 & 0.17 & 0.25 & 0.21 & 0.10 & 0.23 & 0.10 \\
\hline \multirow{2}{*}{ TSCC3 } & 150 & 0.44 & 0.62 & 0.61 & 0.64 & 0.94 & 0.65 & 0.64 & 0.13 & 0.31 & 0.10 & 0.12 & 0.21 \\
\hline & 300 & 0.52 & 0.61 & 0.35 & 0.06 & 0.65 & 0.87 & 0.06 & 0.65 & 0.20 & 0.06 & 0.07 & 0.09 \\
\hline NMAS1 & & 0.51 & 0.58 & 0.41 & 0.50 & 0.56 & 0.33 & 0.46 & 0.56 & 0.34 & 0.06 & 0.13 & 0.10 \\
\hline NMAS2 & & 0.52 & 0.49 & 0.51 & 0.60 & 0.53 & 0.39 & 0.59 & 0.65 & 0.37 & 0.62 & 0.07 & 0.16 \\
\hline NMAS3 & & 0.36 & 0.32 & 0.23 & 0.46 & 0.36 & 0.12 & 0.54 & 0.57 & 0.09 & 0.42 & 0.85 & 0.12 \\
\hline
\end{tabular}

${ }^{1}$ Standard deviations for the heritabilities were 0.01 for TSCC and $<0.02$ for NMAS in all lactations. Standard deviations for genetic correlations were 0.03 to 0.04 for most estimates, with the highest value of 0.07 between 30 and 300 DIM in the third lactation. Standard deviations for phenotypic correlations were $<0.03$.

Table 5. Heritabilities (on diagonal), genetic correlations (below diagonal), and phenotypic correlations (above diagonal) for analysis between mastitis (MAS1, MAS2, and MAS3) and number of mastitis cases (NMAS1, NMAS2, and NMAS3) in lactations 1, 2, and 3 (with standard deviations in parentheses)

\begin{tabular}{|c|c|c|c|c|c|c|}
\hline Item & MAS1 & MAS2 & MAS3 & NMAS1 & NMAS2 & NMAS3 \\
\hline MAS1 & $0.04(0.02)$ & $0.07(0.02)$ & $0.04(0.01)$ & $0.52(0.16)$ & $0.08(0.02)$ & $0.06(0.02)$ \\
\hline MAS2 & $0.62(0.07)$ & $0.06(0.01)$ & $0.05(0.00)$ & $0.08(0.00)$ & $0.52(0.01)$ & $0.06(0.00)$ \\
\hline MAS3 & $0.37(0.09)$ & $0.86(0.04)$ & $0.08(0.01)$ & $0.04(0.00)$ & $0.05(0.00)$ & $0.46(0.01)$ \\
\hline NMAS2 & $0.62(0.07)$ & $1.00(0.00)$ & $0.84(0.04)$ & $0.67(0.06)$ & $0.07(0.01)$ & $0.07(0.00)$ \\
\hline NMAS3 & $0.37(0.08)$ & $0.87(0.04)$ & $1.00(0.00)$ & $0.44(0.07)$ & $0.85(0.04)$ & $0.10(0.01)$ \\
\hline
\end{tabular}




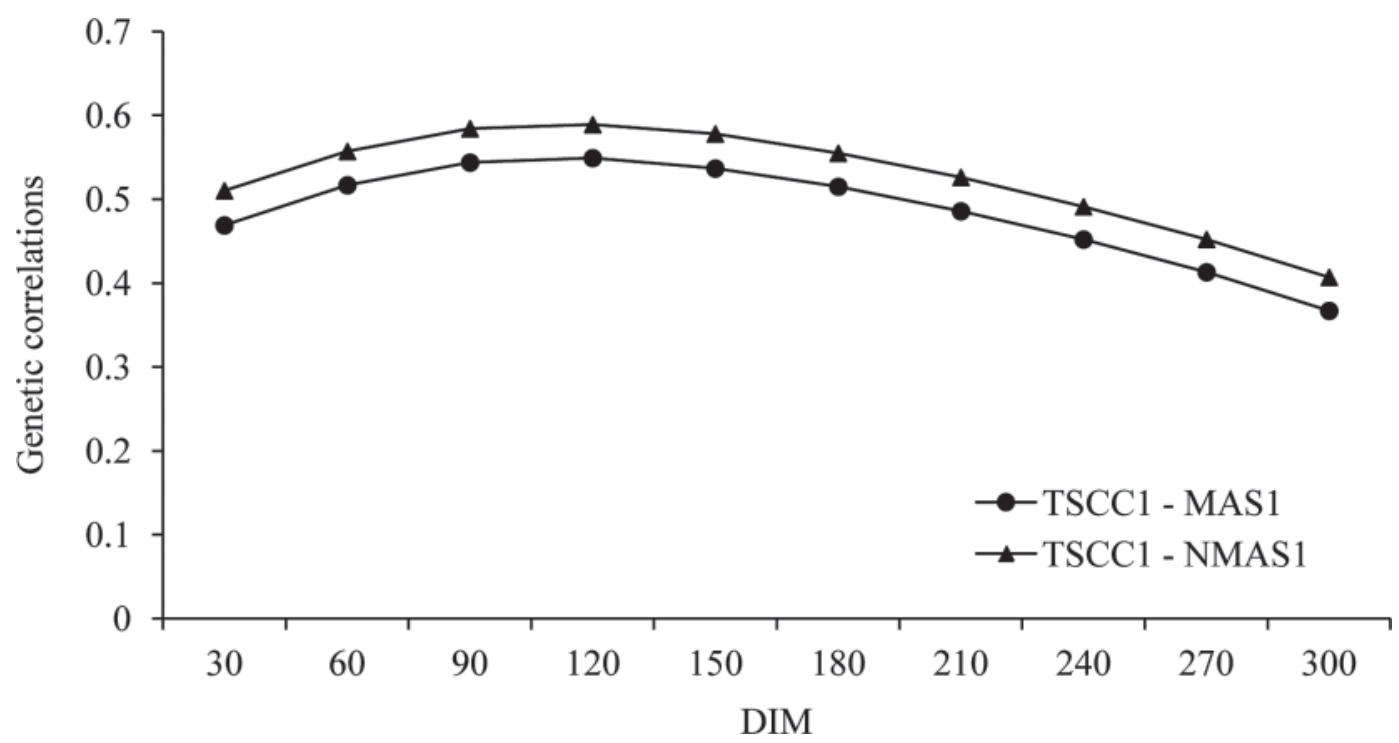

Figure 3. Genetic correlations between $\log _{\mathrm{e}}$-transformed SCC (TSCC1) and mastitis as a binary trait (MAS1) or the number of cases of mastitis (NMAS1) over DIM in lactation 1.

peaking at $90 \mathrm{~d}$, and decreased gradually toward the end of the lactation, with a more pronounced decrease in the third lactation, whereas in the second lactation, genetic correlations tended to be highest in early lactation and decreasing thereafter with stage of lactation. Genetic correlations between TSCC and NMAS were similar to those between TSCC and MAS, in all 3 lactations (Table 4 and Figures 3, 4, and 5). Genetic correlations were $0.53,0.61$, and 0.68 between 305 -d lactation TSCC with MAS, and corresponding estimates with
NMAS were $0.58,0.59$, and 0.55 in first, second, and third lactations, respectively.

The genetic correlations between computed 305-d lactation TSCC and MAS, among all lactations, indicated higher correlations for MAS in the second lactation with TSCC, across all 3 lactations. For instance, the genetic correlation between TSCC and MAS in the first lactation was 0.53 , whereas the genetic correlation between TSCC in the first lactation and MAS in the second lactation was 0.65 .

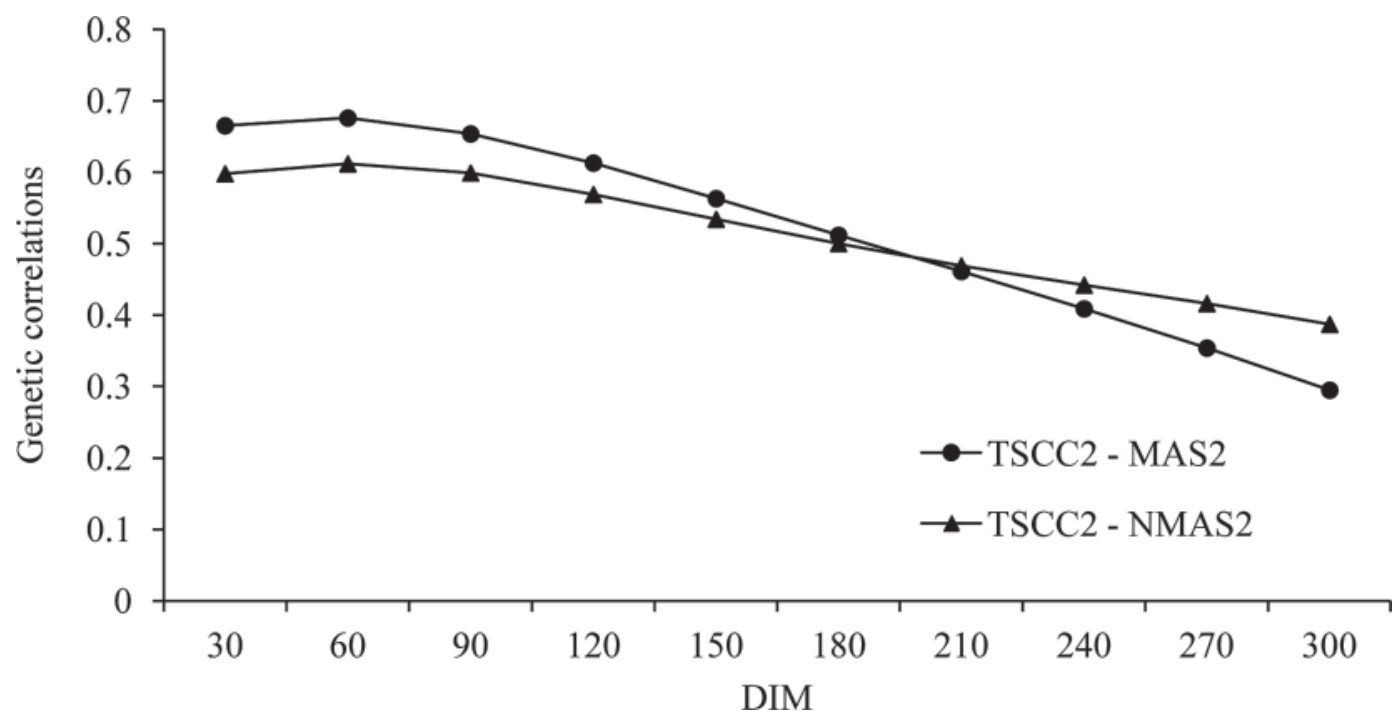

Figure 4. Genetic correlations between $\log _{\mathrm{e}}$-transformed SCC (TSCC2) and mastitis as a binary trait (MAS2) or the number of cases of mastitis (NMAS2) over DIM in lactation 2. 


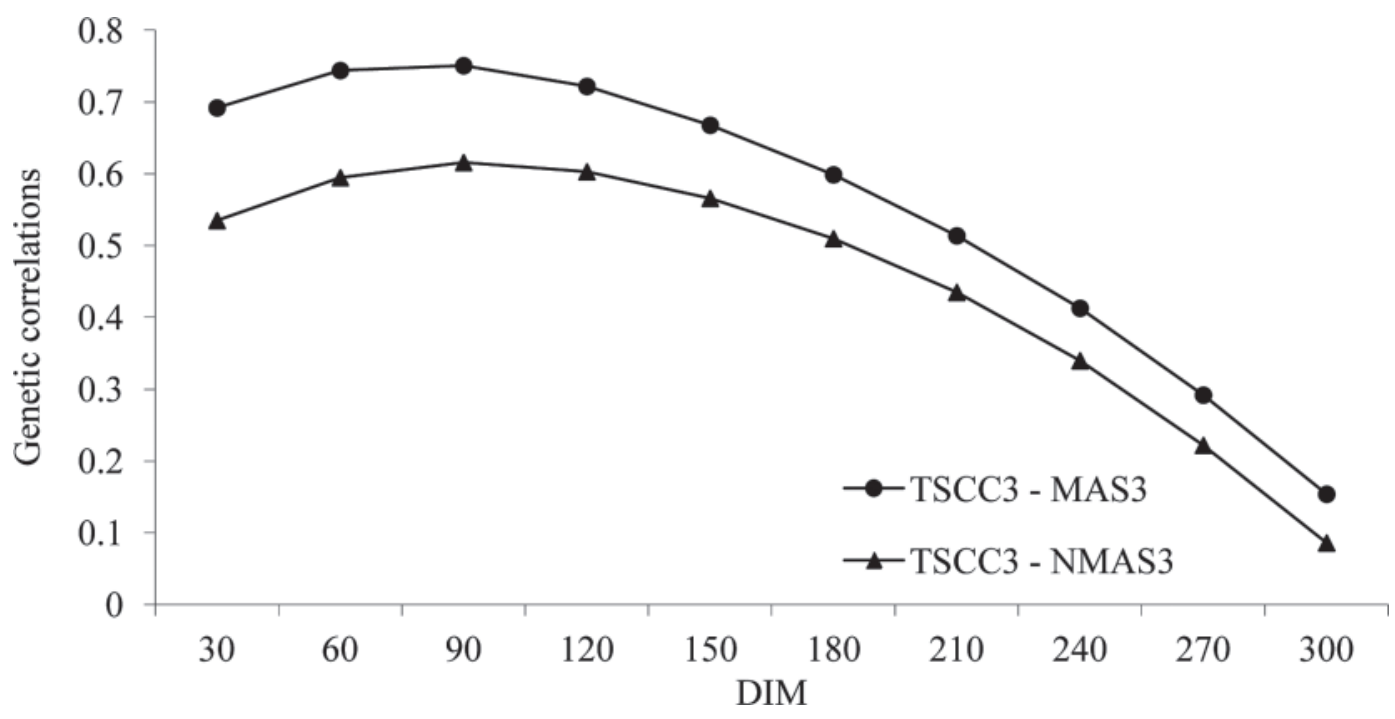

Figure 5. Genetic correlations between $\log _{\mathrm{e}}$-transformed SCC (TSCC3) and mastitis as a binary trait (MAS3) or the number of cases of mastitis (NMAS3) over DIM in lactation 3.

Mastitis as a binary trait and NMAS in the same lactation were highly correlated, with genetic correlations of essentially 0.996 or 1 (Table 5). Also, across the lactations, the genetic correlations among MAS were similar to those between MAS and NMAS across the lactations, further confirming that both traits are genetically the same.

\section{Phenotypic Correlations}

Similar to genetic correlations, the estimates of phenotypic correlations between TSCC at different DIM within lactations were highest between adjacent DIM (0.48 to 0.52 ; Tables 3 and 4 ). These decreased to low values of about 0.12 as DIM got further apart. The patterns of these correlations were generally similar in each of the lactations. The estimates of phenotypic correlations for TSCC between lactations 1 and 3, and 1 and 2 (Table 3 ) were low, varying from 0.10 to 0.20 . The estimates between lactations 2 and 3 tended to be generally higher and more varied, with values ranging from 0.01 to 0.36 . The correlations tended to be highest between the same stages of lactation across the lactations. The phenotypic correlations between TSCC with MAS or NMAS at different DIM within lactations were low at about 0.06 to 0.22 and generally showed little variation within lactations. The phenotypic correlations between MAS or NMAS across lactations were generally low and ranged from 0.04 to 0.09 (Table 5). The phenotypic correlations between MAS and NMAS in the same lactation were of medium value (0.46 to $0.52)$.

\section{DISCUSSION}

\section{Incidence of Mastitis}

In the present study, the mastitis frequency was $16.7 \%$ across lactations, which reflects the greater effort applied by farmers in recording since the investigatory study of Kadarmideen et al. (2000), where a much lower mastitis frequency of $6 \%$ was found across 5 lactations. Higher incidence rates $(38.2 \%)$ have been reported from UK veterinary studies on mastitis (Whitaker et al., 2004) and it is commonly reported that farmer-recorded health events are lower than veterinary-recorded health events (Whay et al., 2003).

The frequency of mastitis and the proportion of cows with more than 1 mastitis case during a lactation increased with lactation number, which was also observed in previous studies. Carlén et al. (2005) found mastitis frequencies of 10,12 , and $15 \%$ for first-, second-, and third-lactation Swedish Holstein cows, respectively. These were lower incidences than in UK data; however, the observation period was shorter (for the period of $10 \mathrm{~d}$ before calving to $150 \mathrm{~d}$ from calving). For UK data, the frequency of mastitis in the first $150 \mathrm{~d}$ from calving was similar to that in the study of Carlén et al. (2005) for the first lactation (10\%) but slightly higher for second (14\%) and third (18\%) lactations. In the same study, mastitis frequencies of 15,18 , and $22 \%$ for lactations 1 to 3 were due to a longer observation period of up to $700 \mathrm{~d}$. Higher mastitis frequencies were reported by Heringstad et al. (2004) of 21, 26, and 31\% for first-, second-, and third-lactation Norwegian dairy cows, respectively, for an observation period of similar 
length to this study ( $30 \mathrm{~d}$ before calving to $300 \mathrm{~d}$ after calving).

Preliminary analysis of mastitis data revealed a peak in mastitis incidence at the start of lactation, particularly in the first lactation. Most new infections take place during the periparturient period when mammary glands undergo transition to a state of active milk synthesis (Mulligan and Doherty, 2008). Intramammary pressure is expected to be a predisposing factor to mastitis due to considerable fluid accumulation as parturition approaches, which leads to dilation of the teat canal and leakage (Sordillo and Streicher, 2002). As well, during the periparturient period innate and acquired defense mechanisms are at their lowest (Mallard et al., 1998). Leukocyte types associated with the immune response in the mammary gland have been found to have either decreased or impaired function at this time (Sordillo and Streicher, 2002). The decreased immune response at calving time could partly be explained by a negative energy balance, due to cows having the inability to consume sufficient feed to meet their metabolic demands. For heifers, starting their first lactation, there are demands from the growing calf up to parturition: the production of mammary tissue and milk synthesis, in addition to the animal's requirements for its own growth. Also, in general, a tendency exists for high yield to be associated with elevated mastitis risk. The increasing incidence with lactation number could be explained by the higher yields produced by older cows at risk of negative energy balance. Also, with maturity and increased stage of lactation, physiological damage to the teats and udder are likely to contribute to increased risk to mastitis infection (Lund et al., 1999). Udders are prone to become more pendulous as the cow matures, caused by high yields and loosening of the main tendon holding the udder, and this can cause hindrance to movement and make the cow more prone to udder injury.

\section{Heritabilities}

The estimates of daily heritability have been shown to increase with stage of lactation for TSCC and were generally higher in later lactations compared with the first lactation. Similar patterns and estimates were reported in an earlier study on UK data (Mrode and Swanson, 2003), although the estimates obtained were lower than those in the current study. Such a difference could be attributed to a smaller data set used in the earlier study and model differences. However, the results obtained were similar to those reported by Haile-Mariam et al. (2001) based on Australian data. Higher daily heritability estimates in later lactations have also been observed by Negussie et al. (2010).
Heritability estimates of MAS were low, ranging from 0.05 to 0.09 . Heritability estimates increased with lactation number, which could be due to the higher proportion of animals treated, as heritability estimates from linear models fitted to binary/categorical traits depend upon frequency level (Heringstad et al., 2000). Heritabilities of MAS in this study were mostly higher than those found in previous studies using linear models (Heringstad et al., 2000; Carlén et al., 2004; Bloemhof et al., 2009). Our heritability estimates were, however, similar to those obtained by Negussie et al. (2010), also from a combined analysis with test-day SCC by RRM, in Danish Holstein cows with estimates of 0.05, 0.06, and 0.07 in lactations 1 to 3 . The analysis of MAS implies that animals with 1 mastitis event are equally at risk for mastitis as those animals with multiple cases; thus, it is perceived that there is a loss of information when the trait is treated as binary (Heringstad et al., 2003; Vazquez et al., 2009).

Higher heritability estimates were obtained by accounting for repeated cases of mastitis compared with analyzing mastitis as a binary trait, which could be explained by more variability observed among cows. However, results from other studies have obtained higher (Pérez-Cabal et al., 2009), the same (Vazquez et al., 2009), or lower (Sørensen et al., 2000) heritability estimates for mastitis as a count trait compared with a binary trait. The definition of mastitis, as either a binary or count trait, has been found to have differing effects on sire rankings (Pérez-Cabal et al., 2009; Vazquez et al., 2009), and it has been suggested that the definition of mastitis should depend upon the selection goal. Pérez-Cabal et al. (2009) explained that if the objective was to discard animals with mastitis problems, then the binary trait would be suitable. However, with regard to overall profitability, due to the known antagonistic relationship between milk production and mastitis resistance and the associated cost of treatments, the number of mastitis events may lead to a greater ability to predict future costs associated with mastitis. However, efficient modeling of mastitis episodes requires good-quality data, which may not be readily available in the UK.

\section{Genetic Correlations}

The genetic correlations between MAS and TSCC were positive and generally moderate to high, indicating that decreasing TSCC also decreases the incidence of mastitis. However, a correlation less than 1 indicates that genetically, they are not the same trait. The joint analysis of TSCC and mastitis could add some useful information. For instance, cows might not be milk sampled concurrent with a mastitis infection and treat- 
ment. In the present study, genetic correlations between TSCC and MAS ranged from 0.37 to $0.55,0.30$ to 0.68 , and 0.15 to 0.75 in first, second, and third lactations, respectively. Negussie et al. (2010) obtained genetic correlations between test-day SCC and mastitis that ranged from 0.46 to $0.65,0.56$ to 0.70 , and 0.54 to 0.67 in first-, second-, and third-lactation cows, respectively. A wider range of estimates were obtained in the present study, generally due to much lower genetic correlations at the end of the lactation, such as the lower value of 0.15 between TSCC and MAS at 300 DIM in the third lactation. The results from the present study also indicate that the genetic correlations between MAS in the second lactation and TSCC in the first lactation are higher than between TSCC and MAS in the first lactation. This is not easy to explain but a similar pattern of results was obtained by Negussie et al. (2010), fitting a model comparable to this study.

Genetic correlations of MAS or NMAS between lactations showed that adjacent lactations (i.e., 1 and 2 , and 2 and 3 ) were more strongly correlated than nonadjacent lactations (i.e., 1 and 3), which is in agreement with previous analyses of Carlén et al. (2004) and Bloemhof et al. (2009). The less-than-unity genetic correlations between lactations suggest that especially first and later lactations should be considered as separate traits. Also, the same trend was observed with TSCC across lactations at the same DIM. The high genetic correlations between lactations 2 and 3 are consistent with the findings of Mrode and Swanson (2003), but in the current study, genetic correlations between lactation 1 and 2 were higher than those between 1 and 3 as would be expected, but the opposite was the case in the prior study. The higher genetic correlation between parities 2 and 3 compared with that between parities 1 and 3 is consistent with the results of Haile-Mariam et al. (2001) and Liu et al. (2001).

Mastitis as a binary trait and NMAS showed unity correlations for the same lactation, which can be explained by a very low proportion of animals with more than 1 episode of mastitis in the data. However, even though both MAS and NMAS appeared to be virtually the same trait, correlations with TSCC tended to be slightly (although not significantly) different.

\section{Implications}

In general, reliability of breeding values for mastitis resistance are expected to be low in the UK. About $23 \%$ of UK milk-recorded herds had records for mastitis and after editing procedures, half of these remained for analysis. Future work would involve encouraging farmers to record health events, as well as providing standardized protocols for recording mastitis health events, so that greater amounts of quality data are obtained. Education of farmers on the benefits of disease recording for their own herd management, in addition to the use of data in genetic evaluations, may result in greater effort in recording, and the data received would be more valuable for genetic evaluation.

\section{CONCLUSIONS}

This study indicates that the joint analysis of TSCC and mastitis across the first 3 lactations is feasible and seems an optimum way to use all available information. The genetic parameters obtained were in line with other studies. A test-day model that accounts for the variations in heritabilities and genetic correlations throughout the lactation for SCC in combination with mastitis as a direct trait is expected to result in more accurate evaluations compared with the currently used repeatability model for lactation average SCC.

\section{ACKNOWLEDGMENTS}

The authors acknowledge the farmers recording the data and funding from Defra (London, UK) under the Sustainable Livestock Production LINK Programme, the Scottish Government (Edinburgh, UK), Cattle Information Service (CIS, Watford, UK), Cogent (Chester, UK), DairyCo (Warwickshire, UK), Genus (Cheshire, UK), Holstein UK (Rickmansworth, UK), and NMR (Chippenham, UK).

\section{REFERENCES}

Banos, G., M. P. Coffey, E. Wall, and S. Brotherstone. 2006. Genetic relationship between first-lactation body energy and later-life udder health in dairy cattle. J. Dairy Sci. 89:2222-2232.

Bloemhof, S., G. de Jong, and Y. de Haas. 2009. Genetic parameters for clinical mastitis in the first three lactations of Dutch Holstein cattle. Vet. Microbiol. 134:165-171.

Carlén, E., M. del P. Schneider, and E. Strandberg. 2005. Comparison between linear models and survival analysis for genetic evaluation of clinical mastitis in dairy cattle. J. Dairy Sci. 88:797-803.

Carlén, E., K. Grandinson, U. Emanuelson, and E. Strandberg. 2009. Random regression models for genetic evaluation of clinical mastitis in dairy cattle. Animal 3:1100-1108.

Carlén, E., E. Strandberg, and A. Roth. 2004. Genetic parameters for clinical mastitis, somatic cell score, and production in the first three lactations of Swedish Holstein cows. J. Dairy Sci. 87:30623070 .

Chang, Y. M., D. Gianola, B. Heringstad, and G. Klemetsdal. 2004. Longitudinal analysis of clinical mastitis at different stages of lactation in Norwegian cattle. Livest. Prod. Sci. 88:251-261.

Detilleux, J. C. 2009. Genetic factors affecting susceptibility to udder pathogens. Vet. Microbiol. 134:157-164.

Gasqui, P., and J. Barnouin. 2003. Statistical modelling for clinical mastitis in the dairy cow: Problems and solutions. Vet. Res. 34:493-505.

Haile-Mariam, M., P. J. Bowman, and M. E. Goddard. 2001. Genetic and environmental correlations between test-day somatic cell count and milk yield traits. Livest. Prod. Sci. 73:1-13. 
Haile-Mariam, M., and M. E. Goddard. 2010. Preliminary genetic analyses of voluntarily supplied disease data in Australian dairy herds. Anim. Prod. Sci. 50:186-192.

Heringstad, B., Y. M. Chang, D. Gianola, and G. Klemetsdal. 2003. Genetic analysis of longitudinal trajectory of clinical mastitis in first-lactation Norwegian cattle. J. Dairy Sci. 86:2676-2683.

Heringstad, B., Y. M. Chang, D. Gianola, and G. Klemetsdal. 2004. Multivariate threshold model analysis of clinical mastitis in multiparous Norwegian dairy cattle. J. Dairy Sci. 87:3038-3046.

Heringstad, B., G. Klemetsdal, and J. Ruane. 2000. Selection for mastitis resistance in dairy cattle: A review with focus on the situation in the Nordic countries. Livest. Prod. Sci. 64:95-106.

Interbull. 2009. Interbull routine genetic evaluation for udder health traits: August 2009. Accessed May 9, 2011. http://www-interbull. slu.se/udder/framesida-udder.htm.

Kadarmideen, H. N., and J. E. Pryce. 2001. Genetic and economic relationships between somatic cell count and clinical mastitis and their use in selection for mastitis resistance in dairy cattle. Anim. Sci. $73: 19-28$

Kadarmideen, H. N., R. Rekaya, and D. Gianola. 2001. Genetic parameters for clinical mastitis in Holstein-Friesians in the United Kingdom: A Bayesian analysis. Anim. Sci. 73:229-240.

Kadarmideen, H. N., R. Thompson, and G. Simm. 2000. Linear and threshold model genetic parameters for disease, fertility and milk production in dairy cattle. Anim. Sci. 71:411-419.

Kelton, D. F., K. D. Lissemore, and R. E. Martin. 1998. Recommendations for recording and calculating the incidence of selected clinical diseases of dairy cattle. J. Dairy Sci. 81:2502-2509.

Liu, Z., F. Reinhardt, and R. Reents. 2001. Parameter estimates of a random regression test day model for first three lactation somatic cell scores. Interbull Bull. 26:61-65.

Lund, M. S., J. Jensen, and P. H. Petersen. 1999. Estimation of genetic and phenotypic parameters for clinical mastitis, somatic cell production deviance, and protein yield in dairy cattle using Gibbs sampling. J. Dairy Sci. 82:1045-1051.

Lund, T., F. Miglior, J. C. M. Dekkers, and E. B. Burnside. 1994 Genetic relationships between clinical mastitis, somatic cell count, and udder conformation in Danish Holsteins. Livest. Prod. Sci. $39: 243-251$.

Mallard, B. A., J. C. Dekkers, M. J. Ireland, K. E. Leslie, S. Sharif, C. L. Vankampen, L. Wagter, and B. N. Wilkie. 1998. Alteration in immune responsiveness during the peripartum period and its ramification on dairy cow and calf health. J. Dairy Sci. 81:585-595.

Miglior, F., B. L. Muir, and B. J. Van Doormaal. 2005. Selection indices in Holstein cattle of various countries. J. Dairy Sci. 88:12551263.
Mrode, R. A., and G. J. T. Swanson. 2003. Estimation of genetic parameters for somatic cell count in the first three lactations using random regression. Livest. Prod. Sci. 79:239-247.

Mulligan, F. J., and M. L. Doherty. 2008. Production diseases of the transition cow. Vet. J. 176:3-9.

Negussie, E., M. Lidauer, E. A. Mäntysaari, I. Strandén, J. Pösö, U. S. Nielsen, K. Johansson, J.-A. Eriksson, and G. P. Aamand. 2010. Combining test day SCS with clinical mastitis and udder type traits: A random regression joint genetic evaluation model for udder health in Denmark, Finland, and Sweden. Pages 25-32 in Interbull Bulletin 42: Riga, Latvia. Interbull, Uppsala, Sweden.

Neuenschwander, T. F.-O. 2010. Studies on disease resistance based on producer-recorded data in Canadian Holstein cattle. PhD Diss. University of Guelph, Guelph, ON, Canada.

Oltenacu, P. A., and D. M. Broom. 2010. The impact of genetic selection for increased milk yield on the welfare of dairy cows. Anim. Welf. 19:39-49.

Pérez-Cabal, M. A., G. de los Campos, A. I. Vazquez, D. Gianola, G. J. M. Rosa, K. A. Weigel, and R. Alenda. 2009. Genetic evaluation of susceptibility to clinical mastitis in Spanish Holstein cows. J. Dairy Sci. 92:3472-3480.

Philipsson, J., G. Ral, and B. Berglund. 1995. Somatic cell count as a selection criterion for mastitis resistance in dairy cattle. Livest. Prod. Sci. 41:195-200.

Sordillo, L. M., and K. L. Streicher. 2002. Mammary gland immunity and mastitis susceptibility. J. Mammary Gland Biol. Neoplasia $7: 135-146$

Sørensen, M. K., J. Jensen, and L. G. Christensen. 2000. Udder conformation and mastitis resistance in Danish first-lactation cows: Heritabilities, genetic and environmental correlations. Acta Agric. Scand. A 50:72-82.

Vazquez, A. I., D. Gianola, D. Bates, K. A. Weigel, and B. Heringstad. 2009. Assessment of Poisson, logit, and linear models for genetic analysis of clinical mastitis in Norwegian Red cows. J. Dairy Sci. 92:739-748.

Whay, H. R., D. C. J. Main, A. J. F. Webster, and L. E. Green. 2003. Assessment of the welfare of dairy cattle using animal-based measurements: Direct observations and investigation of farm records. Vet. Rec. 153:197-202.

Whitaker, D. A., A. I. Macrae, and E. Burrough. 2004. Disposal and disease rates in British dairy herds between April 1998 and March 2002. Vet. Rec. 155:43-47.

Zwald, N. R., K. A. Weigel, Y. M. Chang, R. D. Welper, and J. S. Clay. 2004. Genetic selection for health traits using producerrecorded data. I. Incidence rates, heritability estimates, and sire breeding values. J. Dairy Sci. 87:4287-4294. 